\title{
A novel frame-shift deletion in FANCF gene causing autosomal recessive Fanconi anemia: a case report
}

\author{
Soheila Zareifar ${ }^{1}$, Hassan Dastsooz ${ }^{2}$, Mahdi Shahriari ${ }^{3}$, Mohammad Ali Faghihi ${ }^{4}$, Golsa Shekarkhar ${ }^{5}$, \\ Mohammadreza Bordbar ${ }^{1}$, Omid Reza Zekavat ${ }^{1}$ and Nader Shakibazad ${ }^{1,6^{*}}$ (D)
}

\begin{abstract}
Background: Fanconi anemia (FA) is a heterogeneous genetic disorder characterized by congenital anomalies, early-onset bone marrow failure, and a high predisposition to cancers. Up to know, different genes involved in the DNA repair pathway, mainly FANCA genes, have been identified to be affected in patients with FA.

Case presentation: Here, we report clinical, laboratory and genetic findings in a 3.5-year-old Iranian female patient, a product of a consanguineous marriage, who was suspicious of FA, observed with short stature, microcephaly, skin hyperpigmentation, anemia, thrombocytopenia and hypo cellular bone marrow. Therefore, Next Generation Sequencing was performed to identify the genetic cause of the disease in this patient. Results revealed a novel, private, homozygous frameshift mutation in the FANCF gene (NM_022725: c. 534delG, p. G178fs) which was confirmed by Sanger sequencing in the proband.

Conclusion: Such studies may help uncover the exact pathomechanisms of this disorder and establish the genotype-phenotype correlations by identification of more mutations in this gene. It is the first report of a mutation in the FANCF gene in Iranian patients with Fanconi anemia. This new mutation correlates with a hematological problem (pancytopenia), short stature, and microcephaly and skin hyperpigmentation. Until now, no evidence of malignancy was detected.
\end{abstract}

Keywords: FANCF, Novel mutation, NGS, Autosomal recessive Fanconi Anemia

\section{Background}

Fanconi anemia (FA) is a clinically and genetically heterogeneous uncommon autosomal recessive disorder with hallmarks of congenital malformations, early-onset bone marrow failure, and a high susceptibility to malignancies due to genomic instability $[1,2]$. FA is resulted from disease-causing mutations in FANC genes. FANC genes encode a group of proteins, which act in the pathway of DNA-damage repair along with other proteins. Up to now, 22 FANC genes have been identified among which FANCA mutations, known as hyper-mutable

* Correspondence: nshakibazad@gmail.com

${ }^{1}$ Hematology Research Center, Shiraz University of Medical Sciences, Shiraz, Iran

${ }^{6}$ Pediatric Hematology and Oncology, Bushehr University of Medical

Sciences, Bushehr, Iran

Full list of author information is available at the end of the article genes, have been reported to be the most common genetic causes of FA patients.

The confirmation of FA diagnosis in a proband should be considered with the following examination: Firstly, cytogenetic examination with increased levels of chromosomal breaks and radial formation on lymphocytes after exposure to Diepoxybutane (DEB) or Mitomycin C (MMC) and secondly, identification of pathogenic mutations in one of the 22 FA genes [3-5].The aim of our study was to discover the mutated genes in an affected Iranian patient with FA using Next Generation Sequencing (NGS).

\section{Case presentation}

A 3.5-year-old girl, Caucasian, who was a product of a consanguineous marriage (first-degree cousins, Fig. 1 (timeline of case presentation) and Fig. 2a) was registered in our department due to petechia and nose 


\section{Timeline}

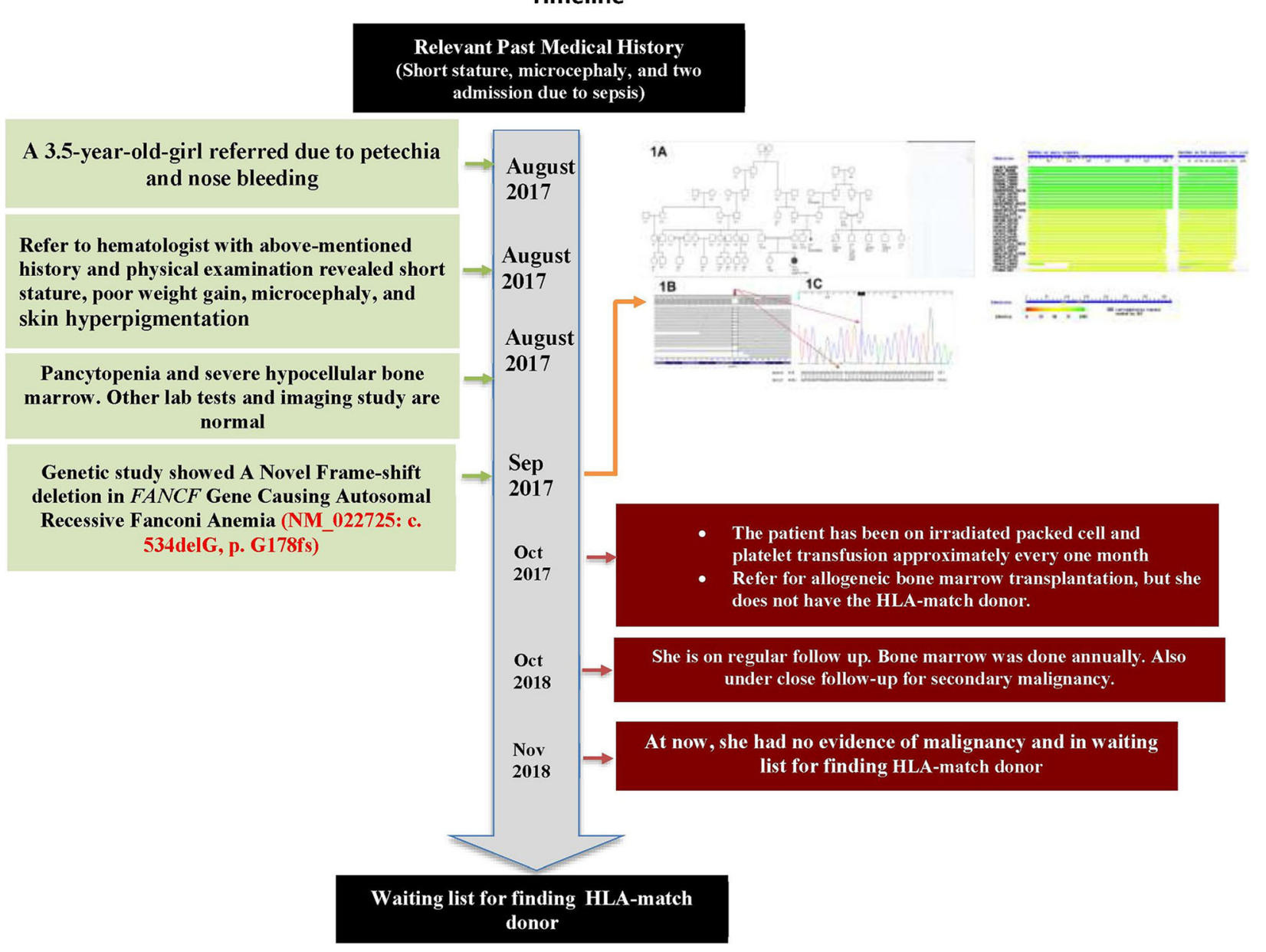

Fig. 1 Information from this case report organized into a timeline figure

bleeding. She was born at 37 weeks and 5 days of normal vaginal delivery. Her birth weight, head circumference, and height were $2.8 \mathrm{~kg}, 32 \mathrm{~cm}$, and $46 \mathrm{~cm}$, respectively. Although her development was in the normal range, the growth chart revealed that her height and head circumference were below the third percentile line, and her weight was around the 5th percentile line. In addition, she took zinc supplements due to her short stature. On physical examination, short stature, poor weight gain, microcephaly (head circumference; $46 \mathrm{~cm}$ ) and skin hyperpigmentation were detected. She had a history of two-time hospital admission due to pneumonia.

Due to petechia, complete blood count was performed and the results identified anemia (Hb: $7.2 \mathrm{~g} / \mathrm{dL}$ ), leukopenia (WBC: $1.5 \times 10^{3} / \mu \mathrm{L}$ with an absolute neutrophil count of 455), and thrombocytopenia (Platelet count: $9 \times 10^{3} / \mu \mathrm{L}$ ). Other laboratory and imaging findings, including $\mathrm{C} 3, \mathrm{C} 4$, ANA, dsDNA, CH50, Immunoglobulin level, TORCH study, metabolic panel, biochemistry studies, abdomen and pelvic sonography, brain MRI, lumbosacral and both hands X-ray, and echocardiography were normal. In addition, bone marrow aspiration and trephine biopsy revealed presented megakaryocyte and moderate to severe hypocellular bone marrow.

The patient had been on irradiated packed cell and platelet transfusion approximately every one month. She was a candidate for allogeneic bone marrow transplantation, but she did not have the HLA-match donor. She was under regular follow-up and occasionally referred due to epistaxis or pallor, and received irradiated packed cell and platelet.

\section{Next generation sequencing (NGS)}

Written informed consent was obtained from the parents. Whole blood samples were collected using EDTA tubes. Genomic DNA was prepared from peripheral leukocytes of the patient using the QIAamp DNA Blood Mini Kit (Qiagen, Germany) and then 


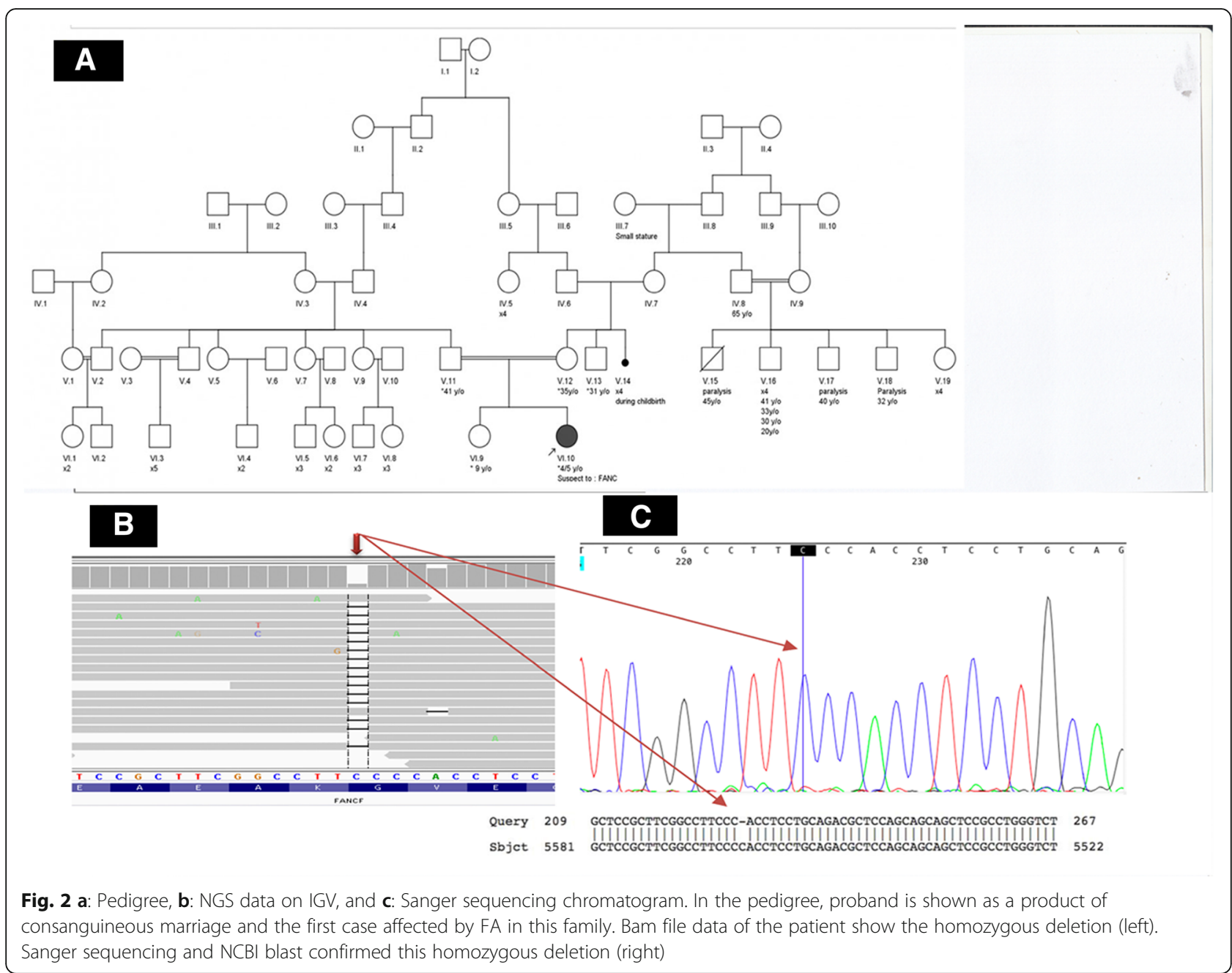

NanoDrop (ND1000, USA) was used to measure DNA concentration.

NGS covering immunological and hematological disorders was carried out on Illumina NextSeq500 machine to the sequence close to 100 million reads. Bioinformatics analysis of the sequencing results was performed using BWA aligner [6], GATK [7] and annovar [8] as well as different databases and bioinformatics software such as REVEL, MCAP, ESP6500,1000G, Clinvar, CADD-Phred, SIFT, PolyPhen, GERP, PhastCons, LRT, Mutation Assessor, Mutation Taster, phyloP46way_placental, phyloP100way_vertebrate, SiPhy_ 29way, FATHMM_pred, RadialSVM, ExAC. Kaviar, GME, gnomAD.

\section{Sanger sequencing}

To confirm the novel identified mutation, we performed Sanger sequencing of the genomic DNA from the proband. For this test, PCR was carried out for the patient's DNA using the following primers: F-FANCF: CGCT GGGAGATTGACATG and R-FANCF: GACCCCAGT CTGTTAGCA (PCR product: $978 \mathrm{bp}$ ) to amplify a mutated region of FANCF. Then, Sanger sequencing was used to sequence amplified DNA with both forward and reverse primers using ABI BigDye Terminator Cycle Sequencing Kit (Applied Biosystems ${ }^{\circ}$, USA). The analysis of Sanger sequencing data was performed with NCBI BLAST and Codon Code Aligner software. Multiple sequence alignment analysis was performed using the SIB BLAST+ Network Service From (https://web.expasy.org/blast/) to compare the amino acid sequence of human FANCF proteins with other proteins across different Kingdoms. STRING (STRING: functional protein association networks, https://string-db.org), tool and KEGG database (KEGG: Kyoto Encyclopedia of Genes and Genomes, http://www.genome.jp/kegg/) were also used to explain the FA pathway and its protein network.

\section{Cytogenetic examination}

Owing to suspicion to inherited bone marrow failure, chromosomal study with MMC on the peripheral blood lymphocyte culture of the proband was requested. To evaluate the types and rates of breakages and rearrange 
ments in the chromosomes of the cells in the proband, GTG banding and the chromosome breakage test were performed on the patient's blood sample. The blood sample was then cultured and treated with different concentrations of MMC.

NGS revealed a novel, private, homozygous, frameshift deletion mutation in the FANCF gene (FANCF-201, ENST00000327470.4, NM_022725: exon1, c. 534delG, p. G178 fs, position 22,625,277 on chromosome 11). Using Sanger sequencing, the mutation was confirmed in the proband as homozygous (Fig. $2 \mathrm{~b}$ and $\mathrm{c}$ ). The identified mutation has not been reported yet in any database of genomic variants including ESP6500, 1000 Genome Project, ExAC, Kaviar, GME, gnomAD, and our internal database (Bayan Gene), confirming the novelty of mutation. This is the first report of FANCF mutation in Iranian patient affected with autosomal recessive FA, complementation group $\mathrm{F}$.

The comparative amino acid alignment of FANCF protein across most kingdoms was also carried out. As shown in Fig. 3, most of the residues were highly conserved during evolution, and any frame shift mutations could be deleterious.

In the cytogenetic study, 100 metaphase spreads were studied from cultures prepared by adding MMC and compared to age-related control. The chromosomal breakage scoring was performed on 5 different slides (one untreated with MMC, one with $150 \mathrm{nM}$ MMC concentration, one with $300 \mathrm{nM}$ MMC concentration and one normal control sample treated with these 2 concentrations of MMC). 25 metaphases were evaluated on each slide for chromosomal aberration (gaps or breaks or radial formations). The results showed about 7-8 breaks/cell on average. In comparison to normal control sample which showed $0.3-0.5$ breakages/cell. There was no radial formation in the normal control sample. The study showed 46, XX with multiple breaks and radial formation (quadri and triradial), compatible with Fanconi Anemia (Fig. 4, Additional file 1).

\section{Discussion and conclusion}

To date, 22 FANC genes have been identified to be mutated in FA patients. The most common genes involved in FA are BRCA2 (FA-D1, 3\%), BRIP1 (FA-J, 2\%), FANCA (FA-A, 60-70\%), FANCB (FA-B, 2\%), FANCC (FA-C, 14\%), FANCD2 (FA-D2, 3\%), FANCE (FA-E, $\sim 3 \%$ ), FANCF (FA-F, 2\%), FANCG (FA-G, 10\%) and FANCI (FA-I, 1\%). However, less common genes are ERCC4 (FA-Q), FANCL (FA-L), FANCM (FA-M), MAD2L2 (FA-V), PALB2 (FA-N), RAD51 (FA-R), RAD51C (FA-O), RFWD3 (FA-W), SLX4 (FA-P), UBE2T (FA-T), XRCC2 (FA-U) [2, 5, 9-12],MAD2L2 (REV7, FANCV) [13], andRFWD3 [14].

Although FA Proteins do not have similar sequences, they are correlated with their association and interactions in a common multi subunit protein

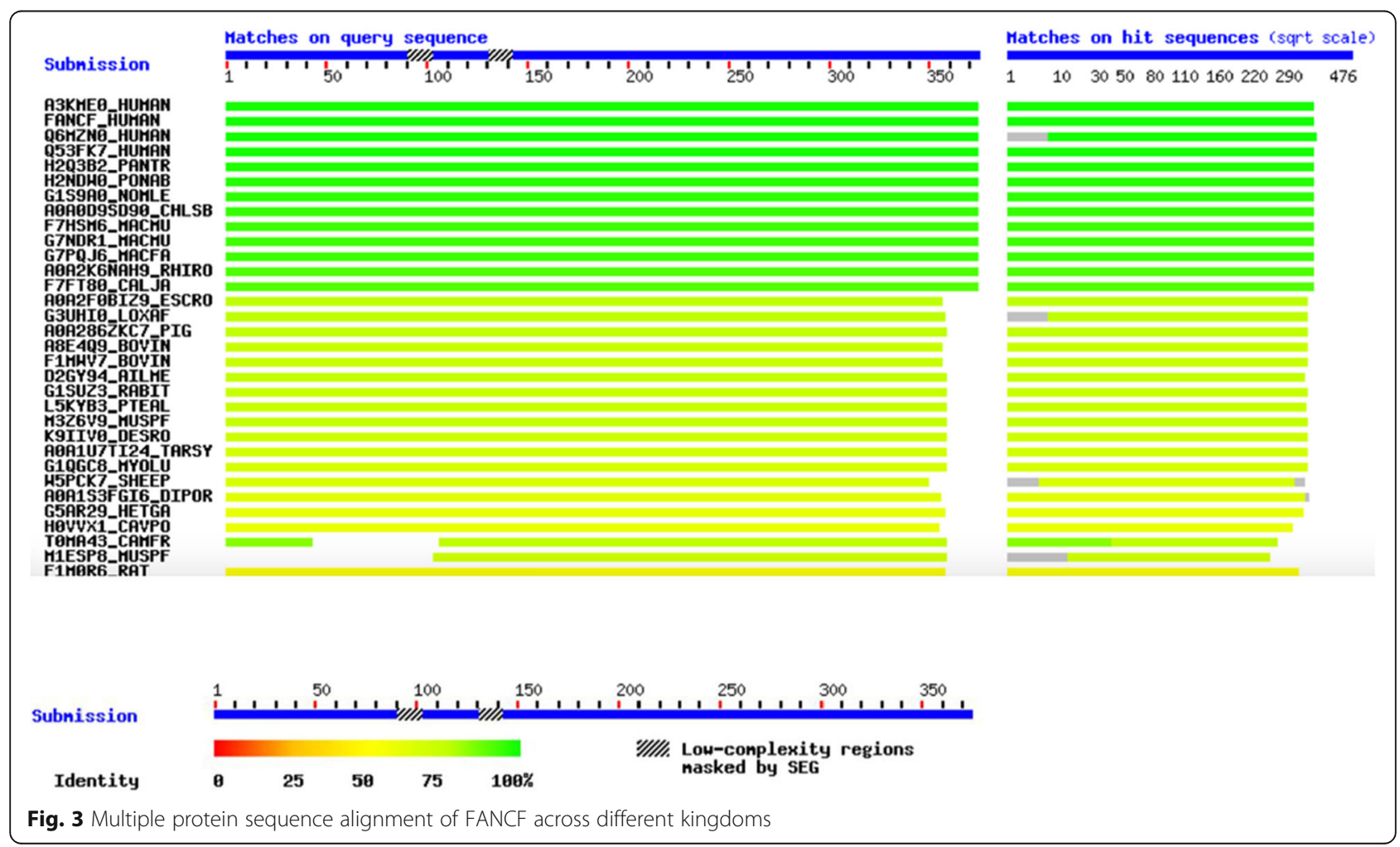




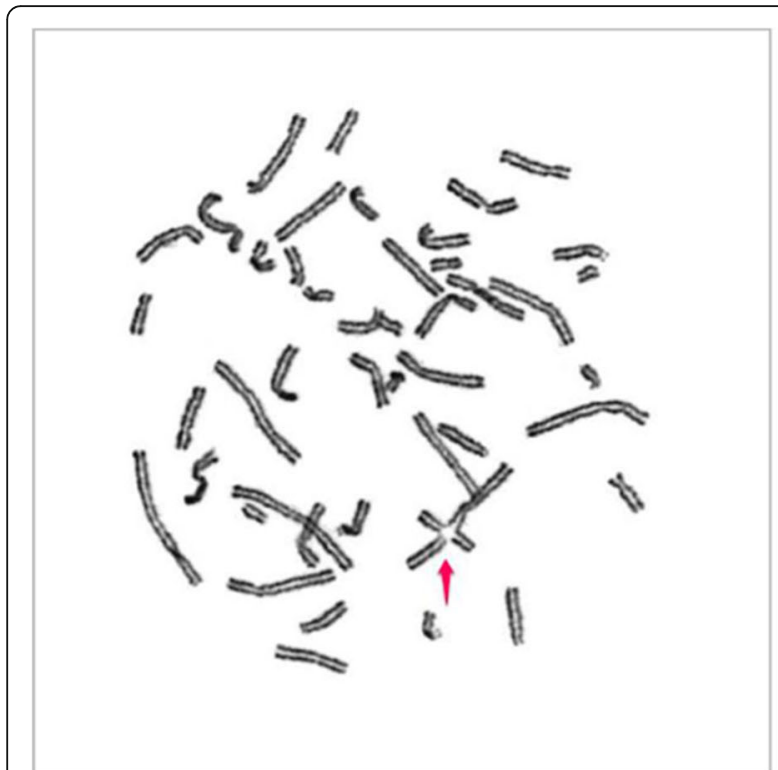

With mitomycin C

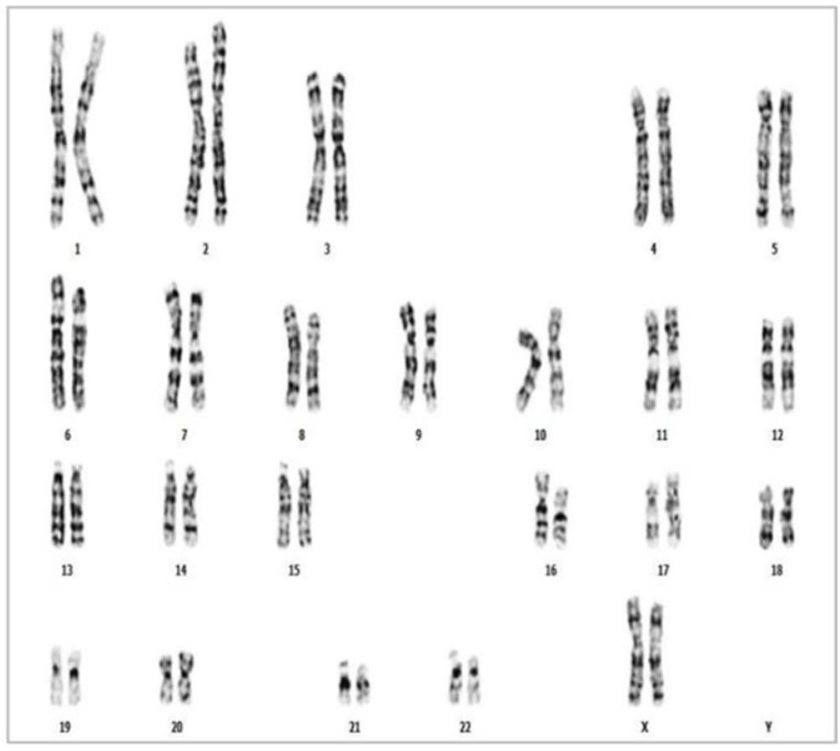

Without mitomycin C

Fig. 4 Comparison of GTG binding between blood cultures, exposure to mitomycin C from the proband and normal control without exposure to this agent

complex. As shown in Fig. 5, which were extracted from STRING (STRING: functional protein association networks, https://string-db.org) tool and KEGG database (KEGG: Kyoto Encyclopedia of Genes and Genomes, http://www.genome.jp/kegg/), different genes are involved in and interact with FA pathways. It can be expected to identify new genes involved in this disorder as the list of its corresponding genes is growing. Since the FA pathway and its components play a vital role in repairing DNA damage, any impairments of these proteins result in life-threatening abnormalities and hypersensitivity to DNA crosslinking agents, leading to a high frequency of chromosomal instability [1].

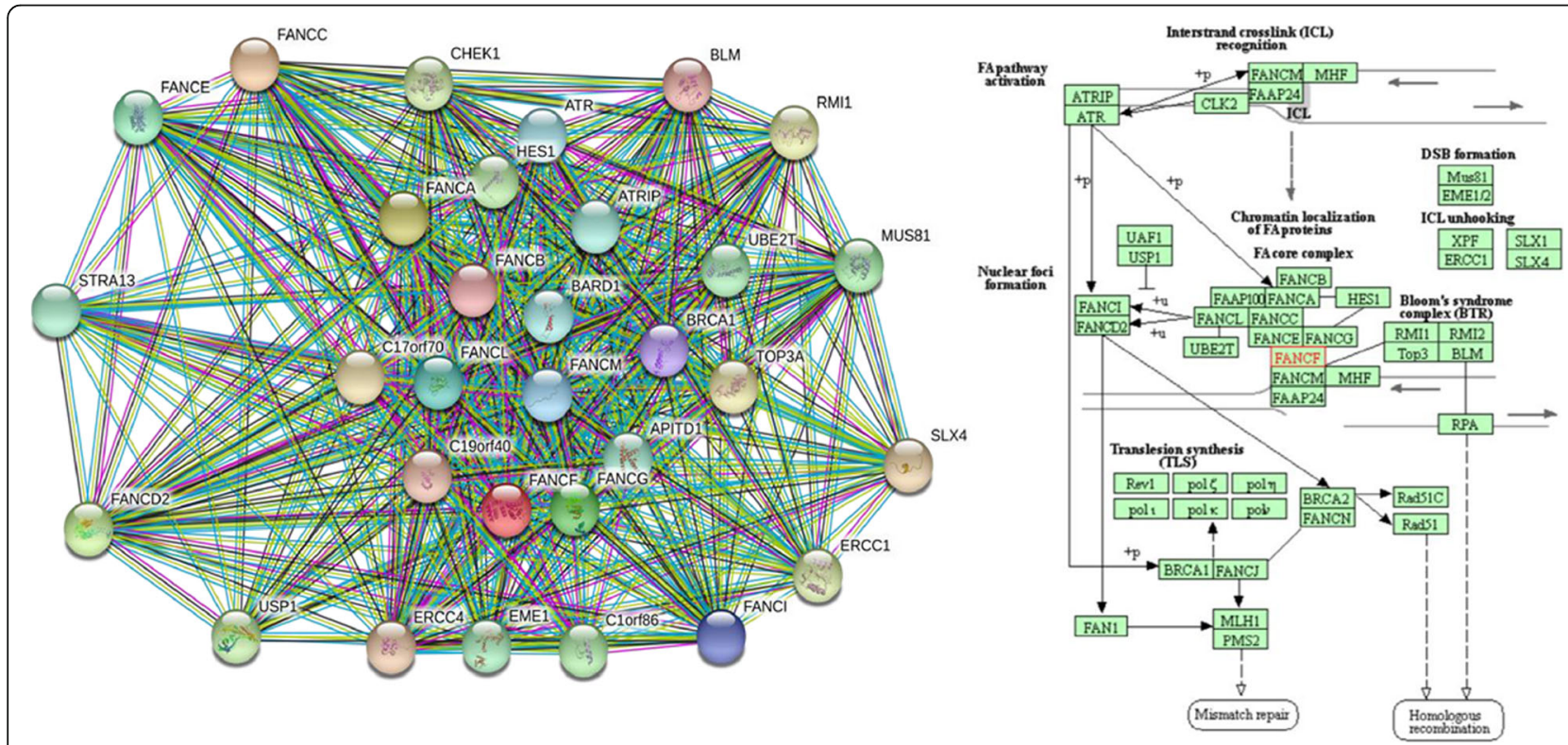

Fig. 5 FA Protein network and its association with other proteins extracted from STRING (left) and FA pathway and different involved genes provided from the KEGG database (right) 
In our study, we identified, for the first time, a novel, private, homozygous frame-shift deletion mutation in FANCF in an Iranian patient with FA. This gene, located on $11 \mathrm{p} 14.3$, is one of the rare genes without intron in the human genome and encodes a DNA repair protein (374 amino acids, 42,254 Da) [15]. The Pfam database indicates that amino acids 1-354 are considered as FANCF domain, while ProDom reported amino acids 1355 as this domain (https://www.ensembl.org). Therefore, most of the amino acids are essentials for proper function of the protein.

The FANCF gene is the only rarely mutated in FA. At present, 14 different pathogenetic mutations of FANCF account for approximately 2 to $3 \%$ of the affected individuals. Disease-associated mutations have been reported throughout the single coding exon of the FANCF gene. The most commonly seen FANCF mutations are short deletions, resulting in frame-shifts and premature termination of the protein. In the study by Nicchia et al. FANCF loss-of-function mutation was associated with a severe phenotype characterized by multiple malformations. FANCF and FANCD2 have been found to be involved in drug-resistant multiple myeloma, ovarian cancer, non-small-cell lung cancer, and head and neck cancer [16-18].

The following evidence can confirm that the identified mutation causes FA in our patient: 1- NGS only identified this mutation to be impaired in the proband and Sanger sequencing confirmed it as homozygous. 2- The novel identified mutation is a frame-shift deletion after the position of 178 in a 374 amino acid protein, coding a fully non-functional truncated protein since most of the amino acids of the FANCF are included in the FANCF domain of this protein. 3- Multiple sequence alignment revealed the conservation of more amino acids of the FANCF during evolution.

FANCF in complex with three FANC proteins, including FANCA, FANCG, and FANCL, interacts with HES1 that is proposed to play a key role in the stability and nuclear localization of the FA core complex proteins. A study conducted by De Winter et al. (2000) [19] identified that FANCF was located primarily in the nucleus, wild-type cells, and a protein complex containing FANCA, FANCC, and FANCG, indicating its role in the maintenance of genomic integrity.

A report of any novel mutation in FANCF and other related FA genes can help shed light on the path mechanisms of this disorder and therapeutic strategies, and establishment of genotype-phenotype correlations. A novel, private, homozygous frameshift mutation in the FANCF gene (NM_022725: c. 534delG, p. G178 fs) in our patient correlated with hematological problem (pancytopenia), short stature, microcephaly, and skin hyperpigmentation. Until now, no evidence of malignancy was detected. The authors of this article intend to do more family and functional study on the proband's relatives. We should also follow the patient for any further somatic mutations or incidence of any type of cancer. If this mutation is reported again in the databases we can make a group and work on genotype-phenotype correlations more practically.

\section{Additional files}

Additional file 1: (Graphical abstract): This image describe and summarize the article in picture version. (TIF $1096 \mathrm{~kb}$ )

Additional file 2: (Consent form): Written informed consent form was signed by the patient's father. (JPG $1497 \mathrm{~kb}$ )

\section{Abbreviations}

DEB: Diepoxybutane; FA: Fanconi anemia; Hb: hemoglobin; MMC: Mitomycin C; MRI: Magnetic resonance imaging; NGS: Next Generation Sequencing; PCR: Polymerase chain reaction; TORCH: Toxoplasmosis, Other (syphilis, varicella-zoster, parvovirus B19), Rubella, Cytomegalovirus, and Herpes; WBC: White blood cells

\section{Acknowledgements}

We would like to thank the patients' family for their willingness to participate in this study. We would like to thank Comprehensive Genetic Center's personnel and physicians for their help and discussion; In addition, we would like to express our deepest appreciation to Mohammad Silawi and Mohaddaseh Rezaeian for providing us the possibility to complete this report. Finally, we would like to express our gratitude to Clinical Research Development Center of Shohadaye-Khalij-e-Fars Hospital and Miss Fatemeh Gholizadeh for editorial assist and the comments they made to improve the paper.

\section{Authors' contributions}

SZ and NSH conceived and designed the study, collected, assembled, and interpreted data and wrote the manuscript. MSH, MB, and ORZ clinically evaluated the patient's interpreted data and wrote the manuscript. HD, MAF, and GSH performed the experiments, interpreted genetic data, and helped with the writing of the manuscript. All authors read and approved the final manuscript.

\section{Funding}

Nothing.

Availability of data and materials

If researchers are willing to access the data, the corresponding author should agree upon providing the interested researcher with the data.

\section{Ethics approval and consent to participate}

Ethic committee at Shiraz University of Medical Sciences, Comprehensive Medical Genetic center has approved the study and parents of the patient have signed written informed consent acknowledging their voluntary involvement in the current study.

\section{Consent for publication}

The patient's father has signed informed consent to participate in this study and to allow us to publish the result of the study (Additional file 2).

\section{Competing interests}

The authors declare that they have no competing interests.

\section{Author details}

${ }^{1}$ Hematology Research Center, Shiraz University of Medical Sciences, Shiraz, Iran. ${ }^{2}$ Italian Institute for Genomic Medicine (IIGM), University of Turin, Turin, Italy. ${ }^{3}$ Division of Pediatric Hematology and Oncology, Department of Pediatric, Shiraz University of Medical Sciences, Shiraz, Iran. ${ }^{4}$ Center for Therapeutic Innovation, Department of Psychiatry and Behavioral Sciences, University of Miami Miller School of Medicine, Miami, USA. ${ }^{5}$ Molecular 
Pathology Center, Shiraz University of Medical Sciences, Shiraz, Iran. ${ }^{6}$ Pediatric Hematology and Oncology, Bushehr University of Medical Sciences, Bushehr, Iran.

Received: 22 November 2018 Accepted: 26 June 2019

Published online: 09 July 2019

\section{References}

1. Deakyne JS, Mazin AV. Fanconi anemia: at the crossroads of DNA repair. Biochemistry Biokhimiia. 2011;76(1):36-48.

2. Joenje $\mathrm{H}$, Patel KJ. The emerging genetic and molecular basis of Fanconi anaemia. Nat Rev Genet. 2001;2(6):446-57.

3. Ishida R, Buchwald M. Susceptibility of Fanconi's anemia lymphoblasts to DNA-cross-linking and alkylating agents. Cancer Res. 1982;42(10):4000-6.

4. Pinto FO, Leblanc T, Chamousset D, Le Roux G, Brethon B, Cassinat B, Larghero J, de Villartay JP, Stoppa-Lyonnet D, Baruchel A, et al. Diagnosis of Fanconi anemia in patients with bone marrow failure. Haematologica. 2009; 94(4):487-95.

5. de Winter JP, Joenje $H$. The genetic and molecular basis of Fanconi anemia. Mutat Res. 2009;668(1-2):11-9.

6. Li H, Durbin R. Fast and accurate short read alignment with burrowswheeler transform. Bioinformatics. 2009:25(14):1754-60.

7. McKenna A, Hanna M, Banks E, Sivachenko A, Cibulskis K, Kernytsky A, Garimella K, Altshuler D, Gabriel S, Daly M, et al. The genome analysis toolkit: a MapReduce framework for analyzing next-generation DNA sequencing data. Genome Res. 2010;20(9):1297-303.

8. Wang K, Li M, Hakonarson H. ANNOVAR: functional annotation of genetic variants from high-throughput sequencing data. Nucleic Acids Res. 2010; 38(16):e164

9. Vaz F, Hanenberg H, Schuster B, Barker K, Wiek C, Erven V, Neveling K, Endt D, Kesterton I, Autore F, et al. Mutation of the RAD51C gene in a Fanconi anemia-like disorder. Nat Genet. 2010;42(5):406-9.

10. Kim Y, Lach FP, Desetty R, Hanenberg H, Auerbach AD, Smogorzewska A. Mutations of the SLX4 gene in Fanconi anemia. Nat Genet. 2011;43(2):142-6.

11. Bogliolo M, Schuster B, Stoepker C, Derkunt B, Su Y, Raams A, Trujillo JP, Minguillon J, Ramirez MJ, Pujol R, et al. Mutations in ERCC4, encoding the DNA-repair endonuclease XPF, cause Fanconi anemia. Am J Hum Genet. 2013;92(5):800-6.

12. Lo Ten Foe JR, Rooimans MA, Bosnoyan-Collins L, Alon N, Wijker M, Parker L Lightfoot J, Carreau M, Callen DF, Savoia A, et al. Expression cloning of a cDNA for the major Fanconi anaemia gene, FAA. Nat Genet. 1996;14(3):320-3.

13. Bluteau D, Masliah-Planchon J, Clairmont C, Rousseau A, Ceccaldi R, Dubois d'Enghien C, Bluteau O, Cuccuini W, Gachet S, Peffault de Latour R, et al. Biallelic inactivation of REV7 is associated with Fanconi anemia. J Clin Invest. 2016;126(9):3580-4.

14. Knies K, Inano S, Ramirez MJ, Ishiai M, Surralles J, Takata M, Schindler D. Biallelic mutations in the ubiquitin ligase RFWD3 cause Fanconi anemia. J Clin Invest. 2017:127(8):3013-27.

15. de Winter JP, Rooimans MA, van Der Weel L, van Berkel CG, Alon N, Bosnoyan-Collins L, de Groot J, Zhi Y, Waisfisz Q, Pronk JC, et al. The Fanconi anaemia gene FANCF encodes a novel protein with homology to ROM. Nat Genet. 2000;24(1):15-6.

16. Nicchia E, Benedicenti F, De Rocco D, Greco C, Bottega R, Inzana F, Faleschini M, Bonin S, Cappelli E, Mogni M, et al. Clinical aspects of Fanconi anemia individuals with the same mutation of FANCF identified by next generation sequencing. Birth defects research Part A, Clinical and molecular teratology. 2015;103(12):1003-10.

17. Dong H, Nebert DW, Bruford EA, Thompson DC, Joenje H, Vasiliou V Update of the human and mouse Fanconi anemia genes. Human genomics. 2015;9:32.

18. Yao C, Du W, Chen H, Xiao S, Huang L, Chen FP. Involvement of Fanconi anemia genes FANCD2 and FANCF in the molecular basis of drug resistance in leukemia. Mol Med Rep. 2015;11(6):4605-10.

19. de Winter JP, van der Weel L, de Groot J, Stone S, Waisfisz Q, Arwert F, Scheper RJ, Kruyt FA, Hoatlin ME, Joenje H. The Fanconi anemia protein FANCF forms a nuclear complex with FANCA, FANCC and FANCG. Hum Mol Genet. 2000;9(18):2665-74.

\section{Publisher's Note}

Springer Nature remains neutral with regard to jurisdictional claims in published maps and institutional affiliations.

Ready to submit your research? Choose BMC and benefit from:

- fast, convenient online submission

- thorough peer review by experienced researchers in your field

- rapid publication on acceptance

- support for research data, including large and complex data types

- gold Open Access which fosters wider collaboration and increased citations

- maximum visibility for your research: over $100 \mathrm{M}$ website views per year

At $\mathrm{BMC}$, research is always in progress.

Learn more biomedcentral.com/submissions 